\title{
Lessons Learnt From the Model of Instructional System for Training Community Health Workers in Rural Health Houses of Iran
}

\author{
Mohammadreza Rahbar ${ }^{1, *} ;$ Mina Ahmadi ${ }^{1}$ \\ ${ }^{1}$ Center for Health Networks Management, Ministry of Health and Medical Education, Tehran, IR Iran \\ ${ }^{*}$ Corresponding Author: Mohammadreza Rahbar, Center for Health Networks Management, Ministry of Health and Medical Education, Tehran, IR Iran. Tel: +98-9123300140, Fax: +98- \\ 2166701812, E-mail:mrzrahbar@yahoo.com
}

Received: August 23, 2011; Revised: November 26, 2014; Accepted: November 30, 2014

\begin{abstract}
Background: Many experts believe that the "health houses" of Iran have had major effects in increasing health status of Iranian rural community. One of the factors, which was critical to this success is the employment of young women and men from rural communities who serve as multipurpose health workers. They participate in a two-year task-oriented training course.

Objectives: The purpose of this article was to describe the model of training behvarzes as the community health workers who deliver health services to the health houses of Iran. This description included the specific method of recruiting these CHWs, strategies and methods of their training which is different from general academic education.

Materials and Methods: A descriptive study design was utilized for this analysis in six areas. These areas have been selected according to the expert opinions and experiences of the Center for Health Networks Management.

Results: The results showed the specific method of student selection and clear objectives and standards of training related to the health needs of the community. Recruitment of native human resources, the relationship between training and performance are the characteristics, which have been made this system more efficient and responsive to the health system needs.

Conclusions: Development of the job and task analysis to ensure providing the right training needs, applying more evidences through different studies for reforms, more decentralized equipped system with decision-making tools have been proposed for development.
\end{abstract}

Keywords:Primary Health Care; Community Health Worker; Iran

\section{Background}

In Iran, priority of rural areas in resource allocation was a main policy for primary health care (PHC) system development from the beginning. There are more than 60000 villages, which the average population for them is less than 300 and the average distance between two villages is more than $25 \mathrm{Km}$. Delivering health services to this scattered population was possible by employing a specific community health worker so called "behvarz". Rural health service utilization rates are now the same as in urban areas (1), and it was so that the Iran's health houses have been known by the report of World Health Organization responsible for a sharp drop in mortality and life expectancy increasing (2). One of the main factors had been critical to the success of the Iranian PHC development was feasibility of using young female and male behvarzes from rural communities and training them in district health networks (3). For the time being there are more than 17000 health houses all over the country (4) in which more than 32,000 behvarzes are working (5). In each health house, based on the master plan there should be at least one female behvarz, which covers an average 1000 population (6). As many health experts in the country and outside of it believe that one of the main factors in the success of PHC system is the specific model of behvarz training; we intend to describe the strategies and characteristics of this training system. Moreover, the Iranian health system utilizes the other community health workers with academic education of two years. They consist of family health, disease control and sanitary health technicians. In this article, we have also briefly explained the differences of these educations in comparison to behvarz training system.

\section{Objectives}

The purpose of this study was to describe the specific model of training behvarzes. The behvarz training system has been established to improve special performances in Iranian rural PHC networks. Behvarzes should have the capability to know what, where, when, and how of delivering health services based on defined service packages. Based on the above-mentioned explanations, the objectives of this study are as follows:

- Recruitment method

- Strategies and methods of training

- The process of providing task-oriented media

- Performance evaluation of behvarzes on their job

Copyright (C) 2015, Iranian Red Crescent Medical Journal. This is an open-access article distributed under the terms of the Creative Commons Attribution-NonCommercial 4.0 International License (http://creativecommons.org/licenses/by-nc/4.0/) which permits copy and redistribute the material just in noncommercial usages, provided the original work is properly cited. 


\section{Materials and Methods}

A descriptive study design in six areas as a result of expert opinion was utilized for the analysis of behvarz training system. We also made comparisons between behavarz training system and other academic educations including family health, disease control and environmental health technicians. These comparisons were done by the eligible people who had enough experiences in the health networks and education and were reflected in different instructions issued by Ministry of Health and Medical Education (MoH). Meanwhile, as the training is generally focused on the job-specific knowledge, skill and ability to a person's career or job and is specifically tailored to the job requirements, the overview of a training system should be based on the job and task analysis (7). By applying this logic and with gathering the opinions of the experts, the CHNM (Center for Health Networks Management) in the $\mathrm{MoH}$ of Iran utilizes a six-step evaluation tool to ensure the outcome-based training system development. Utilizing the items of this logic framework can be found in the "Instructions for Behvarz Training", "The Rules for Recruitment of Behvarzes" $(8,9)$ and usually these critical points are being used in the academic curricular development format in undersecretary for medical education.

\subsection{Steps and Areas for the Review of Behvarz Train- ing System}

- Step 1- the students' selection method: This has been considered as the first character in expert opinions and has been stated by the MoH for the universities through the "Instructions for Behvarz Training" $(8,9)$.

- Step 2- health-program standards to compile task inventories for behvarzes: this step determines how much the training system is adapted to the health program standards.

- Step 3- delivery system or media:This was the third critical point has been stated by the instructions for behvarz training (8).

- Step 4-tools for evaluation of learners and performance measures for the tasks: Constructing the tests to evaluate the learner's mastery of the learning objectives was of great importance in the expert opinion. It tells us "Does the behvarz know how to meet the required performance standards for the tasks?"

- Step 5-sequence and structure: This step reviews the instructions for training, including time for different titles and lesson plans.

- Step 6- training conduction and management:The goal of this step is to analyze the ability of training system for effective learning plans.

\section{Results}

In this study, first we described general differences between behvarz and other academic university graduates from those who may serve as the community health work- ers in the health houses. According to the instructions have been stated by $\mathrm{MoH}$, it is possible for 3 groups of the university-educated people to work in the health house. They consist of family health, disease control and sanitary health technicians. A committee of health experts has reviewed the educational curriculums of these people and compared them to the tasks of behvarzes. The results have been stated in the "Instruction for complementary training for health technicians to serve as the health workers in the health house". The review of this document shows that behvarzes are being trained based on service packages; therefore, they are responsive to every current health service package, but the other graduates in academic education need the complementary training as follows (10):

- All these university graduates need complementary courses in health network structures and functions and essentials of working in health house, health education, nutrition, maternal care, school health, geriatrics, oral health, disaster management program.

- The family health technicians need disease control, environmental and occupational additional courses.

- Disease control health technicians need environmental, occupational health and family health courses.

- Environmental health technicians need the occupational health, family health and disease control courses.

In addition, the higher retention of behvarzes in comparison to providers from other regions is the other desirable outcome of choosing behvarzes as the native-health staffs in Iranian health networks (11).

\subsection{Results of the Report From the Six Above-Men- tioned Review Steps}

\subsubsection{Review of the Students' Selection Method}

Reviewing the history of PHC shows that the attitude and motivation were considered much more important than schooling (12). One of the major factors contributing to the success of the country's PHC networks has been the intimate relationship between a behvarz and his/her community (13). Behvarzes are being selected from the community where they live. The recruitment qualification is the selection of those who have passed 11 years general education. They should be indigenous and well-known in their rural areas. A committee in the district health center (DHC) selects the most appropriate candidates. They evaluate the candidates in terms of their abilities to build and maintain the good relationships with people. According to the rules, after a written examination the committee is responsible for selecting the most appropriate people through an interview.

\subsection{Review of the Health Program Standards to Compile Task Inventories for Behvarzes}

In the second step, we reviewed the availability of the health program standards to design the behvarz training 
Rahbar M et al.

system. We selected a maternal health program as an example for this review. We found the tasks of behvarzes related to this health program in different documents like as the books of the "Explanation of the services of health team" and "Maternal care educational package". Reviewing the maternal health program showed that there were 16 different diseases as the target health problems for prevention and management in the cares for pregnant women (14). One of these diseases was preeclampsia. The activities related to diagnosis and management of preeclampsia and prevention of eclampsia were extracted from service packages and the expected knowledge and behavior of these activities have been shown as follows:

1. Educating mother about signs of preeclampsia and sequels of eclampsia

2. Measurement of blood pressure in each visit

3. Examination of ankles and legs for edema in every visit

4. Referring the client to a specialist in the event of:

- Diastolic blood pressure greater than $90 \mathrm{~mm} \mathrm{Hg}$

- Unusual weight gain

- Edema in lower limb

5. Advising the mothers with preeclampsia in choosing the hospital for delivery

6. Checking the referred mother for the results of the specialist's visit

The review of the training package for maternal care shows the related educational topics to acquire the needed knowledge and skills. The review of other training packages and learning objectives in them shows a taskoriented training system based on the service packages.

\subsection{Review of the Delivery System or Media}

The CHNM has produced training packages for training delivery system. The training packages consist of 4 books and a multimedia for the trainers. Moreover, the instructional settings for behvarz training include classroom training, on job training and finally distance learning. The classroom training includes group discussion, role playing, and practices in the sample health house. The trainers in Behvarz Training Centers are being trained about these issues through the training package of "The Methods and Techniques for Training" (15). The continuous education after graduating from BTC will be accomplished by the trainers and upper levels during the supervisory visits for monitoring the performances of the health house. There are also at least 5 hours of training each month by BTC and DHCs based on needs assessments and also for new and changed services. There is a national quarterly journal for the behvarz training on the basis of national needs assessments and most of the universities have a regional journal on the basis of their regional needs.

\subsection{Review of the Tools for Evaluation of Learners and Performance Measures for the Tasks}

The training package of "Instructional evaluation" has been considered as the reference for BTCs for this issue (16). In this step, we asked ourselves "Does the behvarzes meet the required performance standards for the task?" For an outcome-based training course we need to evaluate behvarzes in terms of their actions in the field. The review shows the behvarz training course includes a noticeable time of field exercises. Subsequently, the continuous education after graduating from BTC will be focused on the field performance of this health staff. In the line of a real performance measure, the BTCs are responsible for supervisory visits and also receiving feedbacks from other health experts who are responsible for supervisory visits in the health houses. Therefore, the performance measures include a variety of different methods to evaluate the skills and actions of behvarzes in their field (8). The supervisory checklists are one of the tools, which evaluate the performance of these health workers.

\subsection{Review of the Sequence and Structure}

The review of the instructions for behvarz training shows a wide explanation about sequence and structure. In addition, a training package has been provided for this important issue (17). Through different expert opinions, the national committee of behvarz training determined 20 main areas of training for behvarzes based on the current needs of the rural community and health service packages. The goal of these main areas is training behvarzes for prevention and control of diseases in target age groups of the community. According to the instruction, the training consists of two parts:

- Part 1: includes 1288 hours training. It consists of 405 hours theoretical, 493 hours practical and 390 hours field practice training. The titles of training consist of the preliminary and prerequisite training and introduction to current health programs.

- Part 2: includes 2008 hours of training consists of 420 hours theoretical, 538 hours practical and 1050 hours field practice training. In this step, the content of education is more specified for the practical skills of behvarzes. At the end of this step, behvarzes should pass more field work and so gradually they will be adapted to what they should do in the future.

\subsection{Review of the Training Conduction and Man- agement}

The trainers in BTCs are trained in different issues of training conduction and management (17). Moreover, the instructions for behavarz training have explained the details of conduction and management of the training course.

\section{Discussion}

Considering the number of BTCs, which is now 218 in which 1138 trainers are working (18) and with remembering the fact that during the last 3 decades they have 
trained more than 32000 behvarzes, it seems that we can consider this system as one of the biggest PHC training systems of region which has been established to develop rural community health workers training. Although, the behvarz training in Iran has achieved to a relative perfect development level of an outcome- based training system, but it seems that there is a high potential to reach to a more proper system of training. In this part of this paper, we have brought some discussions and purposes according to the above-mentioned results:

1. Improving task-oriented training through more standardization in service packages and training media

2. Most of the training packages are being compiled in national level. To be more responsive and flexible to changing environment and regional needs, the training system in DHC level should be equipped with decisionmaking tools and techniques and should be more decentralized.

3. The training system should be more bounded sustainably to health system and subsystems, jobs and tasks analysis to develop the instructional system strategies.

4. As in none of the educational packages, we couldn't find developed objective planning; it seems that this training system should develop the learning objectives to the domains of cognitive, affective, and psychomotor.

5. The behvarz training system has not been utilized from different studies in the field of educational economics, distant learning technologies, measuring efficiency in comparison to academic education, students and staffs satisfaction and etc. It seems that more quantitative and qualitative studies are needed for gathering more precise evidences for planning and reforms.

\section{Acknowledgements}

We greatly appreciate the assistance and support of Dr. Kamran Bagheri Lankarani, the Professor of Medical University and Chancellor of Health Policy Research Center of Shiraz University of Medical Sciences.

\section{Authors' Contributions}

Dr. Mohammadreza Rahbar had the main role in study concept and design, acquisition of data, analysis and in- terpretation of data, drafting of the manuscript. Dr. Mina Ahmadi had the role in critical revision of the manuscript for important intellectual content, and study supervision.

\section{References}

1. World Health Organization.. The world health report 2008 primary health care now more than ever-Closing the urban-rural gap through progressive expansion of $\mathrm{PHC}$ coverage in rural areas in the Islamic Republic of Iran.Geneva Switzerland: WHO; 2008.

2. World Health Organization.. A Summary of the 2008 World Health Report "Primary Health Care: Now More Than Ever.Geneva Switzerland: WHO; 2008.

3. Mehryar A. Primary Health Care and the Rural Poor in the Islamic Republic of Iran. 2004. Available from: http:|/info.worldbank.org| etools/docs/reducingpoverty/case/22/fullcase/Iran\%20Rural\%20 Healthcare\%20Full\%20Case.pdf.

4. Khosravi A. Health Profile Indicators in Islamic Republic of Iran, 1st edition. 1st edTehran: Center for Health Networks Development and Health Promotion, MoH, Iran; 2009.

5. Rahbar M. Primary Health Care in Islamic Republic of Iran. 2nd edTehran: Mehr Graphic; 2009.

6. Pileroudi C.. The District Primary Health Care Networks in Iran. 1st edTeheran Iran: UNICEF; 2001.

7. Blanchard PN, Thacker JW. Effective Training-Systems, Strategies, and Practices.: Prentice-Hall, Inc; 2004.

8. Center for Health Networks Expansion and Health Promotion-Deputy for Health, The Instructions for Behvarz Training.; 1998.

9. Deputy for Resource Development and Management and Deputy for Health the Admission Instructions for Behvarz.; 2010.

10. Center for Health Networks Management.. Instructions for Com plementary Training for Health Technicians to serve as the Health Workers in the Health House.Tehran: Ministry of Health; 2010.

11. Javanparast S. Contribution of Community Health Workers to the Implementation of Comprehensive Primary Health Care in Rural Settings, Iran. 2011. Available from: http://www.globalhealthequity. ca/electronic\%20library/Iran\%20Final\%20Project\%20Report.pdf.

12. Maurice HK. An Iranian Experiment in Primary Health Care: The West Azerbaijan Project.1st edUK: Oxford University and Thetford press Ltd; 1983.

13. Shadpour K. Primary health care networks in the Islamic Republic of Iran. East Mediterr Health J. 2000;6(4):822-5.

14. Emami Afshar, Valafar S.. Maternal Health. 1st edTehran: Novin; 2007.

15. Chegini Y, Rahbar M. The Methods and Techniques for Training.Tehran: MoH-UNICEF; 2002.

16. Chegini Y, Rahbar M. Instructional Evaluation. 1st edTehran: $\mathrm{MoH}$ UNICEF; 2002.

17. Chegini Y, Rahbar M. Instructional technology.Tehran: MoH- UNICEF; 2002.

18. Center for Health Networks Management.. The annual report of the Human Resource Management Group.: Ministry of Health; 2011. 